\title{
Relational Communication Behaviors and Related Outcomes in an Online Class
}

\author{
Tracy Callaway Russo \\ University of Kansas, Lawrence, KS, USA
}

trusso@ku.edu

\begin{abstract}
This study investigated how in one graduate genetics class, verbal/textual cues of relational communication were related to perceptions of presence, student performance, and student satisfaction with their learning. Data were gathered from subthread posts to the class discussion site, student responses to a summative survey, and instructor evaluation of performance.

Results of the study indicated a statistically significant regression relationship between frequency of textual relational cue use in subthread postings and performance in the class. There was no significant relationship between cue use and perceptions of presence of the other students, of the instructor, or of selfassessed presence. Similarly, there was no significant relationship between cue use and student satisfaction with their learning.

This pilot study demonstrates the presence and importance of textual relational cues and argues for extension and replication of the examination of the ir role in signaling relationship and engagement in online classes.
\end{abstract}

Keywords: Mediated presence, social presence, communication behaviors, online learning

\section{Introduction}

Along with the increase in the number of students learning remotely through asynchronous online classes, efforts also are increasing to identify components of online learning environments that contribute to or support learning. In particular, because some of the communication processes that support learners in traditional classes are absent or changed in asynchronous classes, teachers, course developers, and frequently the students themselves are interested in understanding how to enhance engagement and support, as well as supporting learning and performance.

Early assessments of computer-mediated communication concluded that because most social cues are absent in text-only contexts, these media would be appropriate for task-related communication but inadequate for relational communication (Culnan \& Markus, 1987; Trevino, Daft \& Lengel, 1990). DeSanctis and Gallupe (1987), for example, argued that computer mediation reduces interpersonal attraction and group cohesiveness by increasing the psychological distance between participants. Cuesfiltered-out research suggests that computer-based, textual communication is not suited to convey relational meanings and that nonverbal codes are best

Material published as part of these proceedings, either on-line or in print, is copyrighted by Informing Science. Permission to make digital or paper copy of part or all of these works for personal or classroom use is granted without fee provided that the copies are not made or distributed for profit or commercial advantage AND that copies 1) bear this notice in full and 2) give the full citation on the first page. It is permissible to abstract these works so long as credit is given. To copy in all other cases or to republish or to post on a server or to redistribute to lists requires specific permis sion from the publisher at Publisher@InformingScience.org suited to this purpose (Donohue, Diez, Stahle, \& Burgoon, 1983). More recently, although some researchers have reported depersonalizing effects of mediated communication, others have argued that well-developed interpersonal relationship may develop online (Baym, 1995; Walther \& Burgoon, 1992). 
The communication behaviors that students and teachers enact, both online and face-to-face, form the basis of others' perceptions of them and, therefore, of how others treat them. Just as in face-to-face contexts, some online students attract the attention of others. It is likely that their ideas also receive more attention. In the same way, some individuals, either face-to-face or online, seem less salient to the interaction, less "present" in the conversation. They and their ideas may receive less attention. This phenomenon has significant implications for online classes. Social presence, the sense that another individual is salient to an online interaction and therefore worthy of attention, has been shown to have significant effect on student satisfaction in mediated classes. It accounted for $60 \%$ of the variance in ove rall learner satisfaction in one study of the use of a text-based medium (Gunawardena \& Zittle, 1997) and showed a significant positive correlation $(r=.44)$ with satisfaction in another study of text-based computer conferencing (Gunawardena \& Duphone, 2000).

Feeling significant in online classroom interaction and feelings that others in that environment are significant thus is related to student satisfaction with online courses. One result of satisfaction arguably is willingness to complete classes and to engage both the material and other students. Addressing the frustrations experienced by learners, instructors, and their institutions, LaRose and Whitten (1999) note the importance of connection in arguing that many Web courses fail to address the leading concern of learners - lack of interaction with the instructor and fellow students. They argue that learner motivation may suffer in Web courses because of a lack of teacher immediacy (LaRose \& Whitten, 2000). Attrition rates in online classes frequently are cited as demonstration that the technical delivery system is inadequate or inappropriate for learning. Although many online classes have little turnover, Moore (1997) has reported attrition rates as high as 50 percent in some online classes. Similarly, Carr (2000) reported that online course completion rates are often 10 to 20 percentage points lower than in traditional courses. As an overt marker of student responses to online classes, attrition rates are a significant indicator. Because of their relationship to such outcomes, the relationship between communication behaviors in online class and satisfaction with the class and between communication behaviors and class performance is the focus of this study.

In the next section, the literature on immediacy and presence will be reviewed, and then a rationale will be presented for using a set of verbal/textual cues as the basis for examination of communication in an online class. Following that, the class and the study's methods will be described and the findings presented. Finally, the results will be discussed, implications and limitations noted, and directions for future research presented.

\section{Immediacy and Presence}

Research on traditional classes has focused on teacher behaviors that connect students with teachers, or teacher immediacy. Immediacy is a function of the psychological distance a communicator puts between himself or herself and the object of his or her communication (Anderson, 1979). The distance between the communicator and a salient target is likely to be smaller than the distance between a communicator and someone who does not seem important in the interaction or who is not salient.

Verbal immediacy is indicated by a variety of behaviors that include calling others by name, using personal examples, and soliciting personal views or opinions (Gorham, 1988). Grammatical and lexical measures that indicate affection, inclusion, and involvement also reflect verbal immediacy (Wiener \& Mehrabian, 1968). Walther and Burgoon (1992) note that research in intimacy indicates that verbal or text components not only convey immediacy but may compensate for the reductions in immediacy that have been assumed in online contexts. In the online classroom where nonverbal cues are not available, cues of verbal immediacy serve as the primary means of establishing psychological connection among participants. 


\section{Immediacy}

The research on immediacy in traditional classrooms supports the argument that when teachers especially but also students enact immediacy behaviors, students are likely to have both positive attitudes about the class (Kelly \& Gorham, 1988; Sanders \& Wiseman, 1990) and enhanced learning (Christophel, 1990; Gorham, 1988; Menzel \& Carrell, 1999; Rodriguez, Plax \& Kearney, 1996). Research on the effects of immediacy and related behaviors in online classes is less clear. Some researchers (Benbunan-Fich \& Hiltz, 1998; LaRose \& Whitten, 1999) have argued that online classes are deficient in actual and perceived student interaction, but others have made a case that online student discussions improved academic performance (Althaus, 1997). Hiltz and Wellman (1997) found that online discussions resulted in increased student satisfaction, in addition to being associated with achievement levels comparable to face-to-face classes. Continued examination of the relationship between perceptions of presence and both affect or satisfaction toward the course and class performance is warranted. This study addresses these issues. Further, it examines the relationship of specific communication behaviors signaling relationship to presence, affect and performance.

\section{Mediated presence}

The construct of immediacy is related to that of mediated or online presence. Although social presence traditionally has been considered a characteristic of a communication medium (Short, Williams \& Christie, 1976), measuring perceptions of presence solely as a function of the medium does not account for the effects of context, task, experience, or individual differences (Picciano, 2002). Indeed, scholars have offered a variety of definitions for presence. Lombard and Ditton (1997) argue that presence is the illusion of nonmediation; a user experiencing a great deal of presence would respond to another individual online as if the medium were absent. According to Tu (2002), social presence is the degree of person-to-person awareness that occurs in a mediated environment. Garrison, Anderson and Archer (2000, cited in Rourke, Anderson, Garrison \& Archer, 2001) define presence as a projection of a person's personality as well as of his or her ideas. Online presence or mediated presence is most fruitfully considered a function of the interaction between a medium and the communication enacted in that context. Mediated presence thus reflects the interaction of medium, context, participants, and participants' communications.

Mediated presence can be described as the sense that others in an online interaction are immediate, salient, "present," or "real." When an individual attends to another online, that other has presence. This is significant in online contexts, just as it is in face-to-face settings, because we are more likely to engage or pay attention to these persons and to discount or ignore those who are not as salient.

In contrast to traditional classes, participants in online classes frequently are limited to text interaction. Although this reduces the amount of information available to participants by eliminating vocalics, no nverbal communication, and most context cues, online text-based communication is arguably not just an impoverished form of spoken language (Garrison, Anderson \& Archer, 2001), but is a separate entity, a form of "talking in writing" (Fahy, 2002) that has elements of both written and spoken communication (Collot \& Bellmore, 1996). Garrison, Anderson and Archer (2001) have argued that, given guidance and structure, text-based communication provides an opportunity for participants to establish social presence. Similarly, Gunawardena, Lowe and Anderson (1997) have made the case that online participants are interacting, behaving in relation to one another, in response to the presence and influence of the others.

\section{Verbal and Textual Cues of Relational Communication}

Applying the literature in interpersonal face-to-face communication to mediated environments and arguing that language and verbal communication may convey relational messages in addition to task messages, Walther and Burgoon (1992) identified a number of verbal/textual cues of relationship communi- 
cation present in computer-mediated communication. These serve as cues for online interactants. Insofar as they convey a sense that another individual in an online environment is salient and worth attending to, it is reasonable to argue that they also signal immediacy or presence. This pilot study begins an examination of these relationships.

\section{Immediacy/affection}

Verbal immediacy (Wiener \& Mehrabian, 1968) incorporates grammatical and lexical measures that indicate affection, inclusion, and involvement. Walther and Burgoon (1992) note that research indicates that verbal or text components not only convey immediacy but may compensate for reductions in immediacy associated with other channels (Argyle \& Cook, 1976; Wiener \& Mehrabian, 1968). Personalizing, by calling an individual by name or signing a post, is argued to enhance immediacy.

\section{Similarity/depth}

This variable represents the degree to which a communicator stresses similarities or the relative familiarity or superficiality of a relationship. As relationships develop, depth, the degree of knowledge about personal information, may increase, as is evidenced through self-disclosure (Knapp, 1984). Therefore, self-disclosure is an example of similarity and depth in the relationship.

\section{Composure/Relaxation-arousal}

These dimensions are indicated through language intensity, intentional misspellings, use of punctuation, capitalization, or related icons (emoticons) (Walther \& Burgoon, 1992). They represent the degree to which participants express calm and relaxation, or in contrast, intensification that indicates arousal.

\section{Formality/informality}

This dimension is evident through forms of address communicators use, lexical surrogates such as "hmmmm" or "yuck" and by overall use of formal expressions. Research has tended to indicate that mediated communication is more formal in general than face-to-face communication, particularly in being largely written (Gibson \& Hodgetts, 1986). However, the lack of turn-taking in virtual teams and groups may enhance informality (Siegel, 1986).

An additional variable that has been found to be significant in examination of online text discussion is sex. Herring (1996) identified a female "epistolary" online style, which was more referential of the other participants and contained more hedges and qualifiers. She also identified a male "expository" style that would use more intensifiers.

In sum, the purpose of this study was to examine the relationship between communication behaviors identified as signaling relationship and variables of presence, class performance, and satisfaction with learning. Based on the literature, the following research questions were posed:

RQ1: To what extent did the posts in this class reflect the verbal/textual cues of relational communication identified by Walther and Burgoon (1992)?

RQ2: What was the relationship between the frequency of verbal/textual cues and subjects' perceptions of other students' presence, the instructor's presence, and the subject's own presence?

RQ3: What was the relationship between the frequency of verbal/textual cues and grade in the class?

RQ4: What was the relationship between the frequency of verbal/textual cues and student s' satisfaction with their learning?

RQ5: Were there differences by sex in presence of the textual cues, student satisfaction, or grades? 


\section{The Class}

This study focused on a spring 2002 class, LFSC 630, Principles of Transmission Genetics: Historical and Modern Perspectives, taught by the second author at the University of Maryland. This class was part of a completely asynchronous online program offering a masters degree in Life Sciences to science teachers in high schools, community colleges and technical colleges. The students did not meet face-toface or by telephone at any point during the term, and no photographs of the students were posted. All postings included the name of the sender.

Twenty-three students were enrolled, 16 women (70\%), and seven men (30\%). All but two were teaching full-time during the course. They were in a wide variety of locations, in all North American time zones; in addition to a number of students scattered across Maryland, they were located in Delaware, Maine, Florida, George, South Carolina, Wisconsin, California, the North Pole, and the Yukon. Several students had taken other courses in this program, but for some this was their first online class.

Course components included:

- Readings - a genetics text, a biography of a significant geneticist and some journal articles

- Problems from the text and others from the instructor, posted weekly

- Online discussion in response to several content or content/thought questions posted each week; students were required to answer two questions weekly. At the end of each unit, the instructor posted a summary of the discussion and provided additional material or focus where necessary.

- An optional weekly synchronous chat, serving much like the instructor's online office hours, where process and content questions were answered. The transcript of the chat was available on the course site for those who could not attend. This was significant because students were as many as five time zones apart.

- Teaching tips, responses to assignments, generated independently or in groups of varying sizes

- Writing assignments, including reflection papers

- Exams

\section{Methods}

The purpose of this study was to explore the relationships between verbal/textual cues of relational communication and student perceptions of presence or immediacy in an online class. Further, it sought to identify relationships between the cues and student satisfaction with their learning and between the cues and class performance.

Multiple methods were used to address the study's research questions. With the permission of the students, posts to the 20 discussions (886 individual posts) were collected. For the purpose of this study, only the subthread postings to the class discussion site were examined. Students were required to respond to two instructor-posted questions for each of the ten weeks of the class. These one-to-many postings were focused on the instructor as the primary audience and on the other class members as secondary audience. Because of their essay style, these were not included in the study. In addition to these required postings, students were able to but were not required to post responses, questions, and comments. These subthreads also were one-to-many, in that all individuals with access to the WebCT site could read all of them. The total number of subthread postings was 342, with an individual range of 1 to 77 postings and a mean of $39(\mathrm{sd}=19.20)$.

These subthread posts were coded for communication behaviors based on Walther and Burgoon (1992). To examine immediacy, the number of posts which addressed a student by name and the number of 
posts which included a signature were counted. To examine similarity, instances of self-disclosure were recorded. Composure/arousal was operationalized as those posts which incorporated intensifiers. These might be exclamation points, use of all caps, and words like Wow. Formality was coded with two categories: greetings such as "Hi everyone," and use of humor. To examine the role of sex in textual cues, qualifiers were identified. These included statements such as "just a thought" or "I've only started on this, but..."

To assess perceptions of presence, students were asked to complete a survey at the end of the course. The survey asked them to rate on a scale of 1-5 (with 5 being the highest) the amount of presence they perceived in the other students and in the instructor, as well as to rate the amount of presence they believed they had in the class. The single items for each presence target were framed in the style of: As you came to the end of the class, what level of mediated presence did you perceive in the other students? This survey also included a single item in which students were asked to rate on a 5-point Likert scale their satisfaction with their own learning in the course.

Learning was operationalized as by percentage of points earned in the class. Although students did earn some points through participation, most of the points reflected performance on homework assignments, including scores on genetics problems, and examinations. Mean percentage of points earned was 88 (range $68-108, \mathrm{sd}=9.9$ ).

\section{Results}

Overall, students reported perceiving fairly high presence in the other students (mean $=3.94$ on a scale of 1-5 where 5 was highest) and in the instructor (mean $=3.94$ ). Their assessments of their own presence in the class was somewhat lower $($ mean $=3.71)$. There were no statistically significant differences in their assessment of the presence of the three targets.

Research question 1 asked to what extent the posts in this class reflected the verbal/textual cues of relational communication identified by Walther and Burgoon (1992). In total, students included 1,172 instances of textual cues in the subthread posts. The mean number of behaviors by student was 55.81 (SD $=52.83$ ), with a range of 0-192. Table 1 reflects the proportions by category and the mean incident by category by student.

\begin{tabular}{|c|c|c|c|c|c|c|c|}
\hline & $\begin{array}{c}\text { Address } \\
\text { by } \\
\text { name }\end{array}$ & $\begin{array}{c}\text { Self- } \\
\text { disclosure }\end{array}$ & Intensifiers & $\begin{array}{c}\text { Informal } \\
\text { greetings }\end{array}$ & Disclaimers & $\begin{array}{c}\text { Asides/ } \\
\text { Humor }\end{array}$ & $\begin{array}{c}\text { Signed } \\
\text { posts }\end{array}$ \\
\hline Min & 0 & 0 & 0 & 0 & 0 & 0 & 0 \\
\hline Max & 56 & 29 & 26 & 27 & 10 & 19 & 61 \\
\hline Mean & 16.71 & 5362 & 5.24 & 4.29 & 3.29 & 4.38 & 16.29 \\
\hline SD & 15.2 & 6.97 & 7.56 & 6.99 & 2.81 & 5.67 & 18.31 \\
\hline Total & 379 & 118 & 109 & 90 & 69 & 92 & 342 \\
\hline \multicolumn{7}{|l}{} \\
\hline
\end{tabular}

Table 1. Number and descriptives of textual relational cues by category

The second research question examined the relationship between the frequency of verbal/textual cues and perceptions of other students' presence, the instructor's presence, and the subject's own presence. Correlation analysis revealed no statistically significant correlations between any of the textual relational cues and any of the three presence variables.

The third research question examined the relationship between the frequency of verbal/textual cues and grade in the class. Regression analysis indicated that a model composed of the seven verbal/textual cue 
categories predicted grade in the class $(\mathrm{F}=3.56, \mathrm{p}=.02)$. None of the cue categories was individually a significant predictor, although referring to others by name neared significance at $\mathrm{t}=2.08, \mathrm{p}=.06$.

Research question four evaluated the relationship between the frequency of verbal/textual cues and student satisfaction with their learning. Regression analysis indicated no statistically significant relationship between a model of the seven cue categories and student satisfaction.

The final research question asked whether there were differences in the findings by sex. Analysis of variance indicated no statistically significant results for any of the cue categories and sex.

\section{Discussion}

This study investigated how in one graduate genetics class, verbal/textual cues of relational communication were related to perceptions of presence, student performance, and student satisfaction with their learning. Data were gathered from subthread posts to the class discussion site, student responses to a summative survey at the end of the course, and instructor evaluation of performance.

Students in this online class enacted a great many textual relational cues. Most frequent cues were referring to another student by name and signing their own names; qualifiers were used least often. The first contribution of this study is its demonstration of the presence of behaviors that are consistent with the verbal/textual cues identified by Walther and Burgoon (1992) as signaling relationships in online contexts.

The finding of a statistically significant relationship between relational cues and course grade is a second significant contribution. This result argues for further examination of communication behaviors and emphasizes the role of subtle or covert behaviors, such as these textual cues, that students may use to interpret relationship and connection. Cognitive engagement may occur not only individually but also through social interaction (Fahy, 2002), especially for adult students. Other scholars (Fulford \& Zhang, 1993; Anderson \& Garrison, 1995; Rourke \& Anderson, 2000) have made similar constructivist arguments that learning is supported and enabled through interaction with others. In addition to direct performance effects such as are seen in this study, perceptions of connection and relationship also may contribute social support that indirectly influences learning and performance by providing encouragement and both content and process-oriented feedback.

In this class, there was no statistically significant relationship between use of textual relational cues and students' self-reported satisfaction with their learning. Asking for a self-report on satisfaction with learning - rather than interaction - focuses subjects' attention on individual outcomes and may evoke polarizing feelings of pleasure and satisfaction or disappointment. Richer data could be derived from multiple items addressing different targets of satisfaction in the learning environment, such as satisfaction with the course material, with one's own learning, with the delivery system, as well as with the interaction with others in the class.

The absence of statistically significant relationships between use of textual relational cues and perceptions of presence raises more questions than it answers. Walther and Burgoon (1992) postulated that these behaviors can convey relational meanings. These authors argue, however, that development of relationships in computer-mediated communication is likely to take longer than in face-to-face contexts because of the time intervals required for asynchronous communication. Thus, it may be that the ten weeks of this class was insufficient to allow students to develop impressions that they interpreted as mediated presence. Another perspective is that students' perceptions of presence were established based, at least in considerable part, on other factors, including the content of their main thread postings, or on behaviors which were not coded in this study. More research into these perceptions and their antecedents or correlates is appropriate. 
The provocative findings of no differences in use of textual cues by sex may reflect a number of factors in this class. The presence in the findings from this study of qualifiers $(n=69)$ such as "just a thought" arguably reflects an interest in continuing dialogue, in encouraging ongoing discussion. Similarly, use of intensifiers $(n=109)$ may reflect both an oral style that would be enacted face-to-face and an effort to signal engagement and connection. Thus, the results demonstrate behavioral moves toward integration and discussion.

Women outnumbered men in this class more than two to one, and several of the men were new to the program and to online learning. The examples of interaction enacted by the veteran students would serve as a fundamental source of their socialization. Thus some of the men may have adopted behaviors that are most often associated with women, such as qualifiers and greetings. The homogeneity of the class also may have influenced this finding. All but one of the students was a full-time science teacher, and their objectives in taking the class were identical: to gain certification through a masters degree. A common objective and shared context, both inside and outside the class, may have inspired the level of relational cues they enacted.

\section{Limitations and Directions for Future Research}

Findings in this study may have been limited by the use of only seven categories of textual relational cues. Given many students' growing familiarity with online classes and certainly with online communication such as email and instant messenger in general, it is appropriate to develop a more detailed coding system that would account for a greater variety of cues. Among those that would be appropriate include technological cues that are increasingly available, such as screen color, emoticons from drop-down menus, or heightened use of abbreviations taken from instant messenger. A more fine-grained examination of textual cues also could incorporate such signals as use of pronouns ("I" vs. "we," for example), individual word signals of intensity such as "very" or "certainly," and individual phrases of qualification such as "kind of," or "perhaps." Further cues might include use of questions, complimenting or expressing appreciation, and use of humor. Both a broader definition of textual relational cues and additional items comprising the categories would provide richer results.

Generalizability from this study is limited because of its small, homogeneous sample. Examination of the use of textual cues in other types of classes with other types of students is in order to provide opportunities to refine measurement and evaluate validity across contexts.

Another limitation of this study reflects the difficulty of operationalizing and measuring presence. In the end, presence is what people perceive it to be, but potential inconsistency in how students interpreted the presence items are likely to have influenced the findings. A multifaceted presence instrument, which examines presence with multiple items reflecting both impressions and reports of specific behaviors would provide richer data. Another useful extension of this research would examine change in use of textual relational cues over time, as classroom dynamics develop. It is increasingly clear that the degree to which online students feel that they are engaged with others influences classroom outcomes, and refinement of our understanding of both process and product of connection and engagement is in order.

\section{References}

Althaus, S.L. (1997). Computer-mediated communication in the university classroom: An experiment with on-line discussions. Communication Education, 46,_158-174.

Anderson, J.F. (1979). Teacher immediacy as a predictor of teaching effectiveness. Communication Yearbook, 3, (pp. 543559). New Brunswick, NJ: Transaction Books.

Anderson, T., \& Garrison, D.R. (1995). Transactional issues in distance education: The impact of design in audioteleconferencing. The American Journal of Distance Education, 9(2), 27-45.

Argyle, M., \& Cook, M. (1976). Gaze and mutual gaze. Cambridge: Cambridge University Press. 
Baym, N.K. (1995). The emergence of community in computer-mediated communication. In S. Jones (Ed.). Cybersociety: Computer-mediated communication and community (pp. 138-163). Thousand Oaks, Ca: Sage.

Benbunan-Fich, R., \& Hiltz, S.R. (1998). Educational applications of CMC: Solving case studies through synchronous learning networks. Journal of Computer Mediated Communication, 4. Retrieved 9/25/02 from the World Wide Web: http://www.ascusc.org/jemc/vol4/issue3/benbunan-fich.html.

Carr, S. (2000, Feb. 11). As distance education comes of age, the challenge is keeping the students. The Chronicle of Higher Education, 46(23). http://chronicle.merit.edu/free/v46/i23/23a00101.htm

Christophel, D.M. (1990). The relationship among teacher immediacy behaviors, student motivation, and learning. Commu nication Education, 39, 323-340.

Collot, M., \& Belmore, N. (1996). Electronic language: A new variety of English. In S.C. Herring (Ed.). Computermediated communication (pp. 13-28). Philadelphia: John Benjamins Publishing Co.

Culnan, M.J. \& Markus, M.L. (1987). Information technologies. In F.M. Jablin, L.L. Putnam, K.H. Roberts, \& L.W. Porter (Eds.) Handbook of organizational communication: An interdisciplinary perspective. (pp. 420-443.). Ne wbury Park, CA: Sage.

DeSanctis, G. \& Gallupe, R.B. (1987). A foundation of the study of group decision support systems. Management Science, $33,589-609$.

Donohue, W.A., Diez, M.E., Stahle, R., \& Burgoon, J.K. (1983, May). The effects of distance violations on verbal immediacy: An exploration. Paper presented at the annual meeting of the International Communication Association, Dallas.

Fahy, P.J. (2002). Use of linguistic qualifiers and intensifiers with a computer conference. The American Journal of Distance Education, 16(1), 5-22.

Fulford, C.P. \& Zhang, S. (1993). Perception of interaction: The critical predictor in distance education. The American Journal of Distance Education, 7(3), 8-21.

Garrison, R., Anderson, T., \& Archer, W. (2000). Critical inquiry in a text-based environment: Computer conferencing in higher education. Unpublished manuscript.

Gibson, J.W., \& Hodgetts, R.M. (1986). Organizational communication: A managerial perspective. Orlando, FL: Academic Press.

Gorham, J. (1988). The relationship between verbal teacher immediacy behaviors and student learning. Communication Education, 37, 40-53.

Gunawardena, C.N. \& Duphorne, P.L. (2000). Predictors of learner satis faction in an academic computer conference. Distance Education, 21(1), 101-117.

Gunawardena, C., Lowe, C., \& Anderson, T. (1997). Analysis of a global on-line debate and the development of an interaction analysis model for examining social construction of knowledge in computer conferencing. Journal of Educational Computing Research, 17(4), 395-429.

Gunawardena, C.N. \& Zittle, F.J. (1997). Social presence as a predictor of satisfaction within a computer mediated conferencing environment. The American Journal of Distance Education, 11.

Herring, S. (1996). Two variants of an electronic message schema. In S.C. Herring (Ed.) Computer mediated communication (pp. 81-106). Philadelphia: John Benjamins Publishing Co.

Kelly, D.H., \& Gorham, J. (1988). Effects of immediacy on recall of information. Communication Education, 37, 1978-207.

Knapp, M.L. (1984). Interpersonal communication and human relationships. Boston: Allyn \& Bacon.

LaRose, R. \& Whitten, P. (2000). Re-thinking instructional immediacy for web courses: A social cognitive exploration. Communication Education, 49(4), 320-338.

Lombard, M., \& Ditton, T. B. (1997). At the heart of it all: The concept of presence. Journal of Computer Mediated Communication, 3(2). Available: http://www.ascusc.org/jcmc/vol3/issue2/lombard.html

Menzel, K.E., \& Carrell, L.J. (1999). The impact of gender and immediacy on willingness to talk and perceived leaming. Communication Education, 48(1),_31.

Moore, G. (1997). Sharing faces, places and spaces: The Ontario Telepresence Project Field Studies. In K.E. Finn, A.J. Sellen, \& S.B. Wilbur (Eds.) Video-Mediated Communication, (pp. 301-321). Mahwah, NJ: Erlbaum. 
Picciano, A.G. (2002). Beyond student perceptions: Issues of interaction, presence, and performance in an online course. Journal of Asynchronous Learning Networks, 6(1). Retrieved 9/16/02 from the World Wide Web: http://aln.org/alnweb/journal/Vol6 1/6 1picciano.htm

Rodriguez, J.I., Plax, T.G., \& Kearney, P. (1996). Clarifying the relationship between teacher nonverbal immediacy and student cognitive learning: Affective learning as the central causal mediator. Communication Education, 45, 293-305.

Rourke, L., \& Anderson, T. (2000). Exploring social communication in computer conferencing. Association for the Advancement of Computers in Education. Unpublished paper.

Rourke, L., Anderson, T., Garrison, D.R., \& Archer, W. (2001). Assessing social presence in asynchronous text-based computer conferencing. Journal of Distance Education, 14(2). Retrieved 9/25/02 from the World Wide Web: http://cade.athabascau.ca/vol14.2/rourke et al.html

Sanders, J.A., \& Wiseman, R.L. (1990). The effects of verbal and nonverbal teacher immediacy on perceived cognitive, affective, and behavioral learning in the multicultural classroom. Communication Education, 39, 341-353.

Short, J., Williams, E., \& Christie, B. (1976). The social psychology of telecommunications. London: John Wiley \& Sons.

Siegel, J., Dubrovsky, V., Kiesler, S., \& McGuire, T.W. (1986). Group processes in computer-mediate communication. Organizational behavior and human decision processes, 37, 157-187.

Trevino, L.K., Lengel, R.H., \& Daft, R.L. (1987). Media symbolism, media richness, and media choice I organizations. Communication Research 14(5),_553-574.

Tu, Chih-Hsiung (2002). The measurement of social presence in an online learning environment. International Journal on ELearning, 1(2), 34-46. Retrieved 9/24/02 at http://web5.infotrac.

Walther, J.B. (1992). Interpersonal effects in computer-mediated interaction: A relational perspective. Communication Research, 19, 52-90.

Walther, J.B., \& Burgoon, J.K. (1992). Relational communication in computer-mediated communication. Human Communication Research, 19(1), 50-88.

Wiener, M., \& Mehrabian, A. (1968). Language within language: Immediacy, a channel in verba communication. New York: Appleton-Century-Crofts.

\section{Biography}

Tracy Callaway Russo. After a 20-year managerial career, Tracy earned a doctorate in Communication Studies from the University of Kansas in 1995. She is Director of KU's Edwards Campus Graduate Program in Communication Studies in the Kansas City metropolitan area, and she teaches classes in new communication technologies, organizational communication, communication theory, and business communication at both Edwards and Lawrence campuses. Her current research interests are communication processes in distance education and distributed organizations and how individuals come to identify in distributed organizational groups.

Before her academic work, Tracy worked for Knight-Ridder Financial Information for 17 years. She was Vice President Editorial, with responsibility for the U.S. newsgathering operation and later Vice President Operations, with responsibility for order processing, installation and repair, and customer support. She has an MBA from the Rockhurst University Executive Fellows program and an MS in RadioTV from Syracuse University. In 2001, she was named a Carnegie Scholar by the Carnegie Academy for the Scholarship of Teaching and Learning. This project was developed while she was a Carnegie Scholar. 